\title{
Characterisation of a thickened tailings beach
}

\author{
KD Seddon ATC Williams Pty Ltd, Australia \\ JK Albee ATC Williams Pty Ltd, Australia
}

\begin{abstract}
A geotechnical investigation has been carried out on the tailings beach of the Sunrise Dam central thickened discharge (CTD) tailings facility. This is believed to be the most comprehensive investigation of a thickened tailings beach so far undertaken.

The investigation was carried out primarily for the purpose of evaluating the liquefaction resistance of the beach. However, additional data were also recovered to enable an assessment of the overall performance of the stack with respect to CTD design predictions. The investigation comprised CPTU and pore pressure dissipation tests, supplemented by shear wave velocity testing. In addition, stand-pipe piezometers were installed to provide information on the phreatic surface, and un-disturbed samples of tailings were recovered and tested for particle size, density, moisture content, and degree of saturation.
\end{abstract}

These results are summarised and compared to predictions, as well as to results previously obtained for other sites. The influence of the effect of suction resulting from partially saturated conditions is discussed.

\section{Introduction}

Sunrise Dam Gold Mine (SDGM) is an AngloGold Ashanti Australia Pty Ltd (AGAA) operation located in arid, semi-desert near Laverton, WA.

The active tailings storage facility at this site comprises a central thickened discharge (CTD) scheme. The investigation that is the subject of this paper was undertaken to evaluate the risk of liquefaction of the tailings within the CTD stack.

\section{Background}

The Sunrise Dam CTD commenced operation in late 1999, at a production rate of around 2 to $2.8 \mathrm{Mtpa}$. The design life of the initial stack was approximately $25 \mathrm{Mt}$ (Williams 2000), but the design has been progressively modified to an expanded capacity and throughput rate, and the tailings storage facility (TSF) is now expected to operate for the remaining life of mine, and store a final total of close to $75 \mathrm{Mt}$. Over recent years the tailings production rate has been of the order of 3.3 Mtpa.

Details of the original design are contained in Williams et al. (2003) and Williams and Seddon (2004). The discharge solids concentration remains in the typical range of 59-61\% (Seddon \& Fitton 2011).

The stack is approximately $2,000 \mathrm{~m}$ in diameter, with a discharge ramp running up from the west side, as shown in Figure 1.

In 2009, excavation of tailings commenced in an area on the south side of the stack to supply feed to a paste fill plant for underground workings. The tailings borrow area can be identified in Figure 1. A view of the tailings borrow area is shown in Figure 2. From this photograph, is can be observed that the deposited tailings have been excavated to an unsupported vertical face, estimated to be not less than $4 \mathrm{~m}$ in height.

When the tailings borrow pit is active, tailings deposition is concentrated in the northern part of the CTD TSF to prevent inundation of the excavation. 


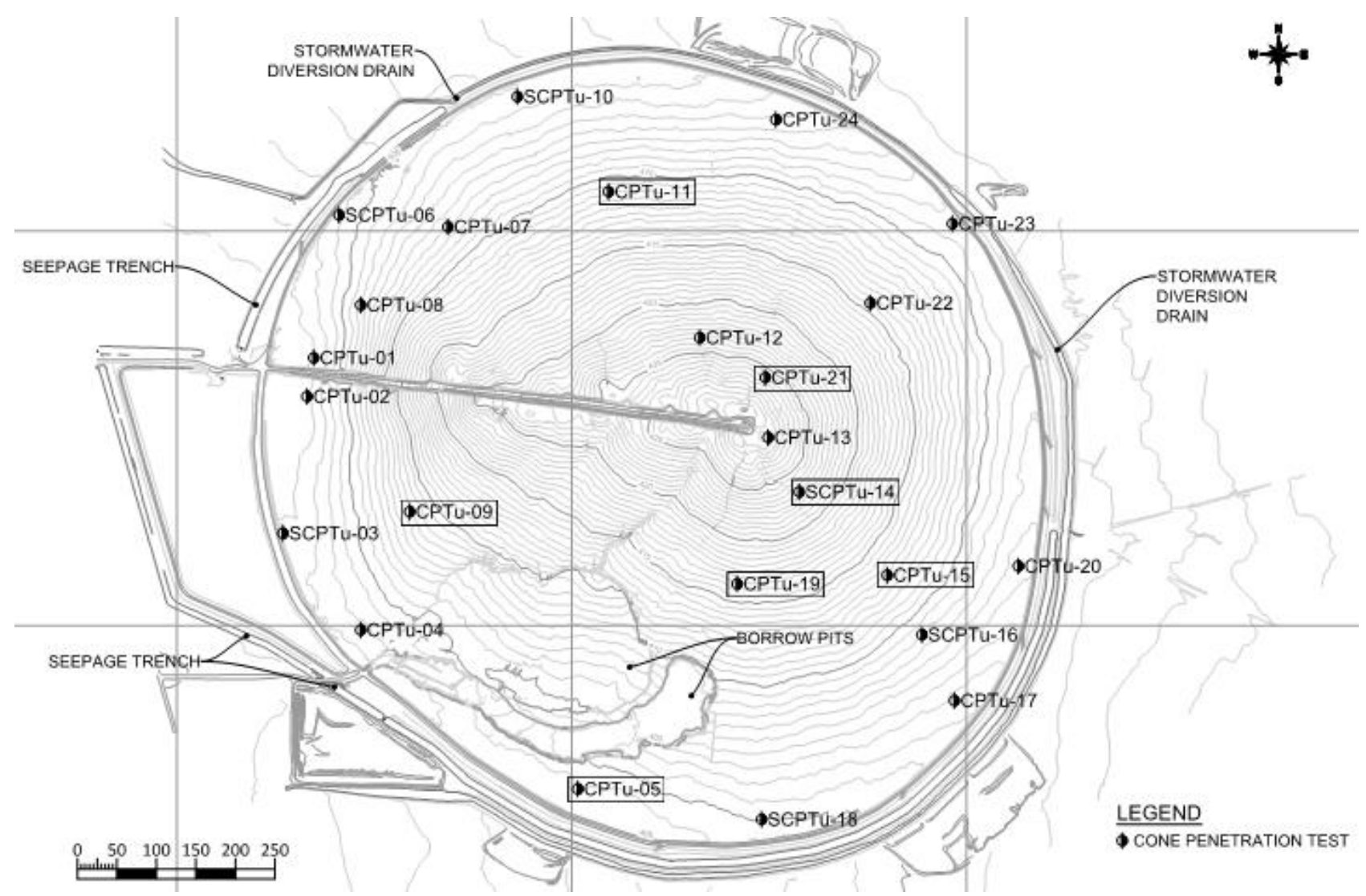

Figure 1 General layout and investigation locations

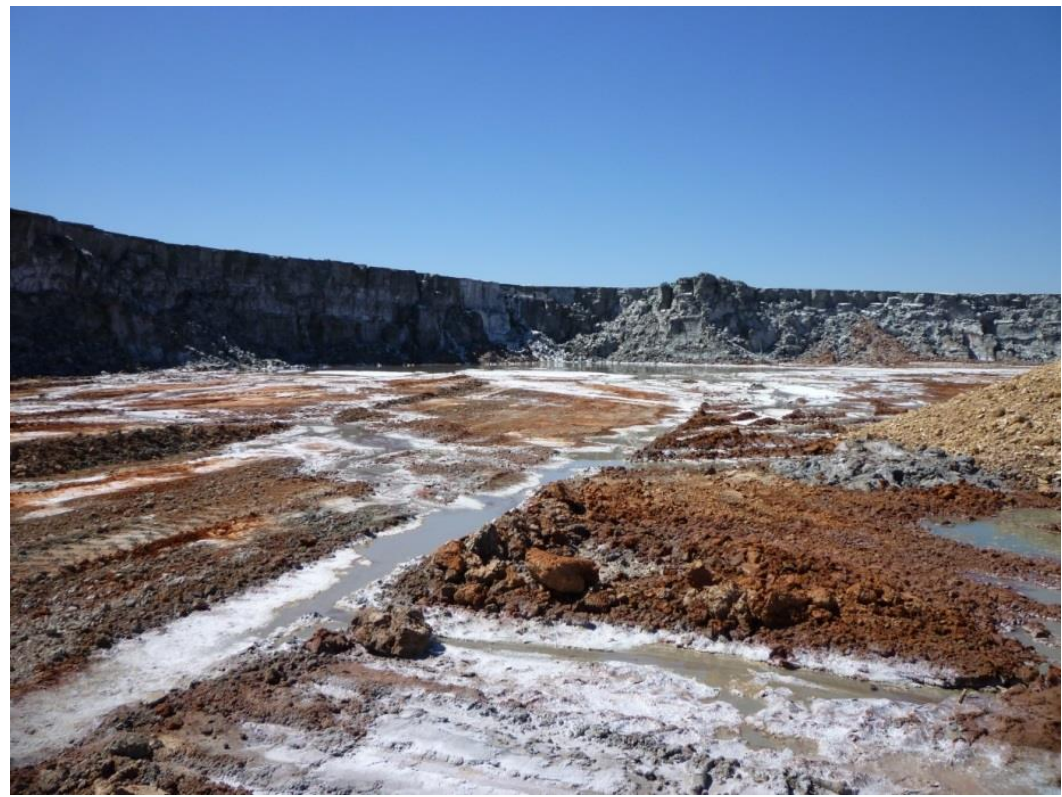

Figure 2 Tailings borrow on south beach area

\section{Characteristics of thickened tailings beaches}

The perceived, desirable characteristics of a thickened tailings beach have been discussed previously by a number of authors, e.g. Robinsky (2000), Williams et al. (2003), Jewell and Fourie (2006), Williams et al. (2008), Seddon and Dillon (2009), and Seddon and Williams (2010). 
The key factors can be summarised as follows:

- The tailings slurry must be thickened to the extent that the deposited tailings are non-segregating on the stack.

- Under this condition, a beach with a relatively uniform slope is expected to form.

- The deposited tailings will achieve a relatively high in situ density under the effects of evaporative drying.

- The deposited tailings will achieve a relatively high strength.

- The deposited tailings will exhibit an enhanced resistance to seismic loading (particularly compared to up-stream raised facilities).

- The strength and trafficability of the beach should have positive implications for closure.

As discussed in Seddon and Dillon (2009), the question of achieved density and strength as listed above is not absolute. Initial deposition on the beach will leave the tailings at a density/moisture content equivalent to the initial settled density. Further drying and strength gain is dependent on the effects of evaporative drying and the influence of the area of the stack on the rate of rise. These are site dependant.

The importance of evaporative drying is that it applies a pre-consolidation pressure (suction) to the tailings at shallow depths. This results in significant density and strength gains in these layers, before they are covered by subsequent deposition (Seddon \& Williams 2010). The deposited tailings then remain over-consolidated until the depth of burial increases to the extent that the overburden stress exceeds the equivalent drying suction. The tailings then revert to a normally consolidated state.

If the net evaporation at the site is high enough, the expectation is that the tailings stack will be unsaturated. Infiltration into the beach will be dependent on climate of the site, but again in areas of high evaporation infiltration is expected to be small to minimal.

\section{$4 \quad$ Investigation}

\subsection{Fieldwork}

The fieldwork was carried out in May 2013, using a contract drilling firm mobilising a low ground pressure rig, Figure 3. Active deposition to the stack continued throughout the investigation; nevertheless, it was possible to access all investigation locations without further special provisions. This in itself is a telling indication of the undrained strength of the beach. This degree of access (over the whole tailings surface) would not be possible on almost any conventional tailings deposit.

Twenty four electric friction cone penetrometer tests with pore pressure measurement ('CPTu') were undertaken to depths between $1.8-25.7 \mathrm{~m}$. These tests were generally terminated in the basement material, with the differences in probe depth reflecting different thickness of tailings at various locations around the site. Dissipation test were undertaken at selected locations. Seismic shear wave tests were performed at six of the sites, and standpipe piezometers were installed in five holes.

Undisturbed soil sampling was undertaken using a 'Mostap' sampler (Brouwer 2007) adjacent to selected CPTu locations. Four bulk samples were also recovered from the beach area.

\subsection{Laboratory testing}

The recovered samples were tested for basic index tests including moisture content, density, particle-size distribution and plasticity. Two selected samples were also tested for consolidated undrained triaxial strength. 


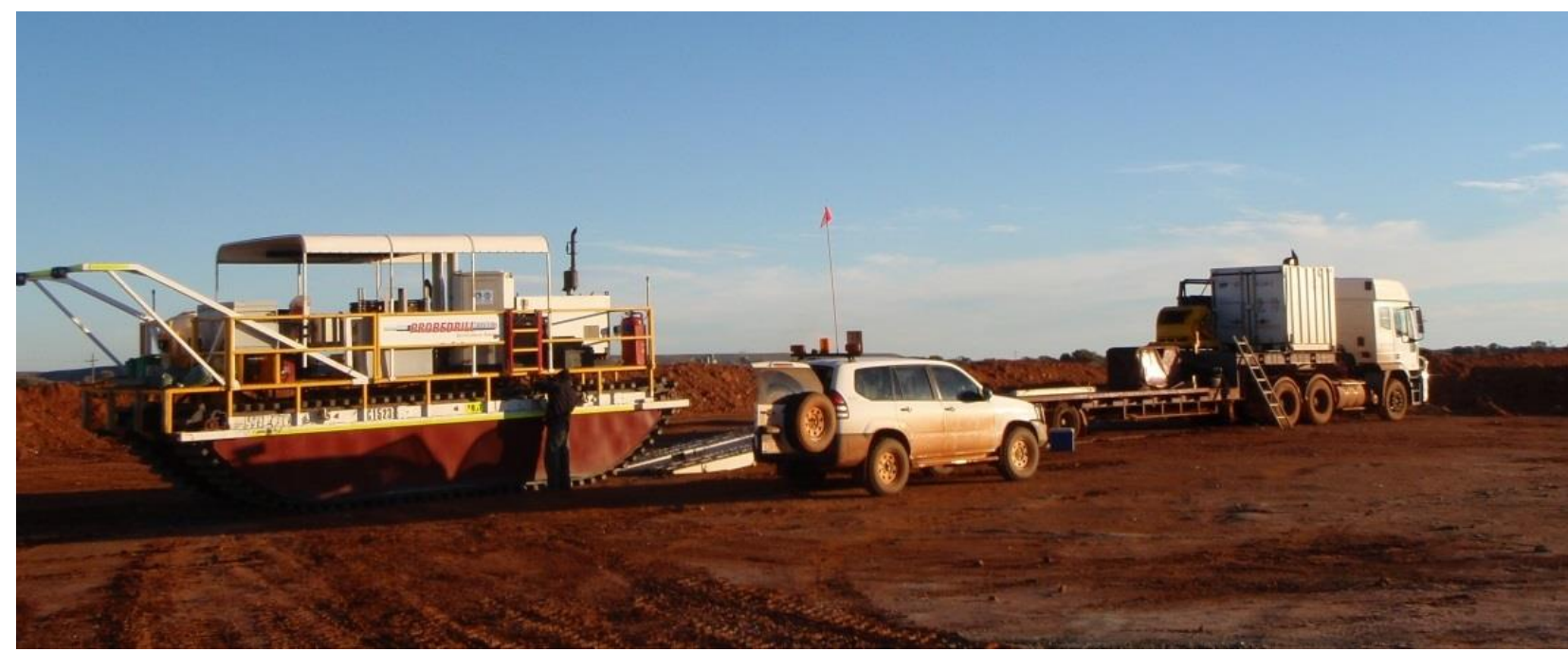

\section{Figure 3 Rig setting up onsite}

\section{Beach profile}

The progressive build-up of the CTD beach profile has been derived from annual survey data, and is shown in Figure 4.

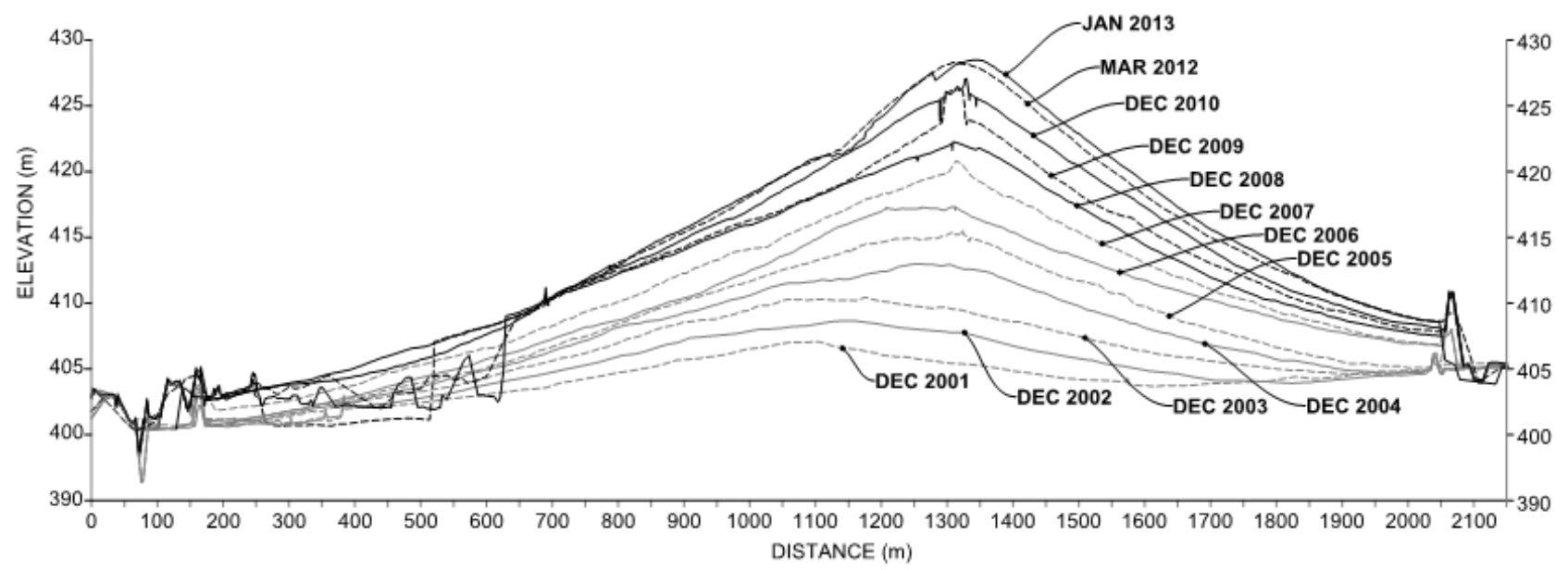

\section{Figure 4 Development of beach profile}

The beach profile for year 2004 was previously reported in Seddon and Fitton (2011). In that year the slope of the upper beach was at $>2 \%$, with an overall slope of around $1.3 \%$. Since that time improvements in thickener operation and management of deposition have resulted in a higher stack, and steeper slopes. From Fig 4 it is apparent that the overall height of the stack is now of the order of 25-30 m, with maximum beach slopes as steep as $4 \%$. More typically, slopes over the upper portion of the stack are around $3 \%$, reducing to about $1.5 \%$ at the edge. The reasons for the occurrence of concave beach slopes relate to the inherent variability of thickener discharge rates and solids concentration, as discussed by Seddon and Fitton (2011).

\section{$6 \quad$ Test results}

\subsection{General}

Testing has shown that the tailings typically have a fines content of about $75 \%$ (material $-75 \mu \mathrm{m}$ ), and are non-plastic. This results in a Unified Classification of 'sandy silt ML'. 


\subsection{Particle-size distribution and segregation}

Particle size data (percent passing $75 \mu \mathrm{m}$ ) at varying distances down the beach from the discharge point is plotted in Figure 5. This indicates very consistent results, with no suggestion of segregation of reduction in particle size with distance.

These results may be compared with data for three different sites, previously presented by Williams (2000) and reproduced in Figure 5 . This also shows the same pattern of consistent particle size down the length of the depositional beach.

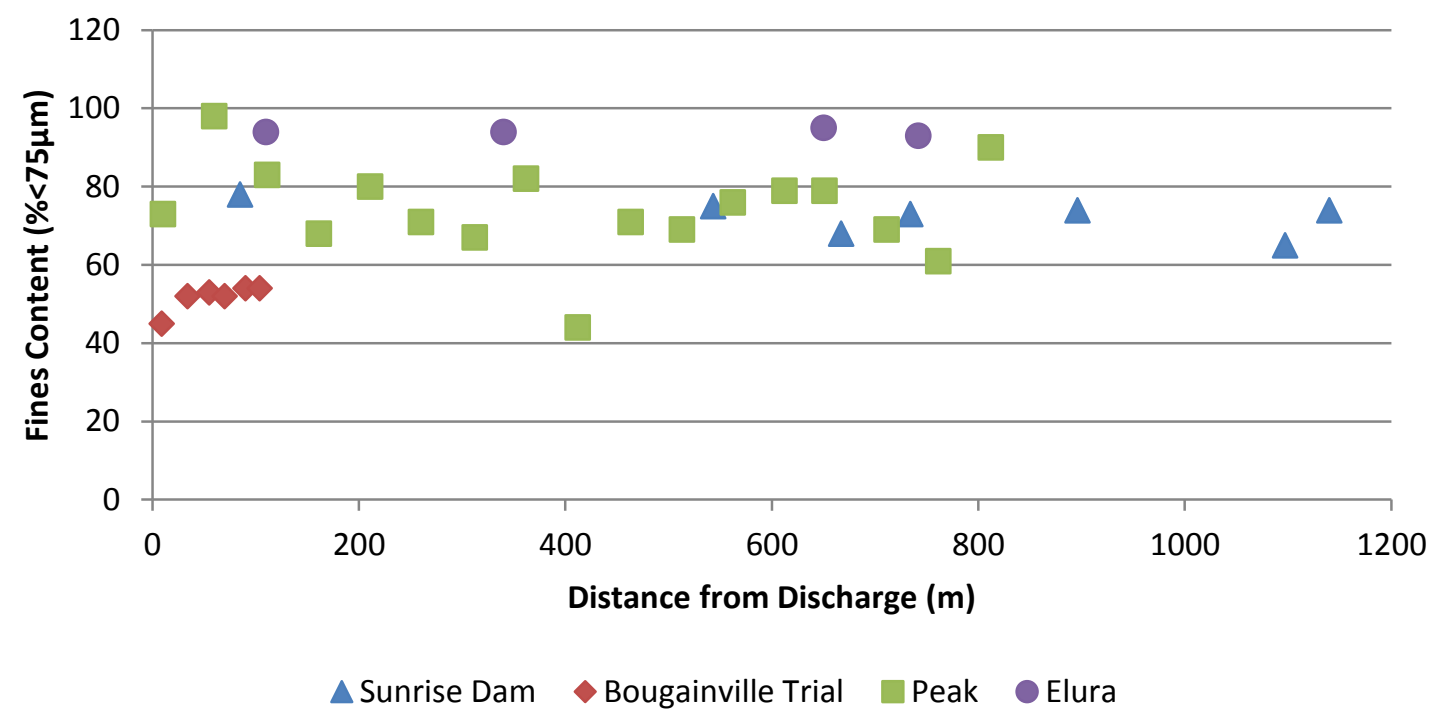

\section{Figure 5 Variation in particle size with distance down the beach}

\subsection{Density, moisture content and phreatic surface}

The process water at this site is hypersaline (except after heavy rain when dilution from surface runoff occurs). The original design dry density at end of filling was assessed at a relatively low $1.5 \mathrm{t} / \mathrm{m}^{3}$. This value was adopted because of concerns that the high salt content would limit the effects of evaporative drying. Based on a reconciliation of mill throughput and total volume of tailings by survey, the achieved average density in 2013 was $1.55 \mathrm{t} / \mathrm{m}^{3}$.

Computations of density achievable due to evaporative drying using the method outlined in Seddon and Dillon (2009) indicate that a somewhat higher density should be achieved if the full evaporation potential could be realised. This supports the expectation of the effect of salt crusting.

Nevertheless, the test results confirm that the beach is unsaturated throughout, with a moisture content typically varying between 15 and $18 \%$. For an in situ dry density of $1.55 \mathrm{t} / \mathrm{m}^{3}$, a moisture content of $18 \%$ represents a saturation ratio of close to $75 \%$. The variation in observed moisture content is attributed to the fact that the stack was operational during the investigation, with the differences reflecting the time duration of drying at individual locations.

The installed water monitoring wells, together with an interpretation of the CPTu results and the dissipation tests, all confirm that the stack is unsaturated. A water-table was encountered in only a limited number of holes, very close to the base of the stack, as shown in Figure 6. 


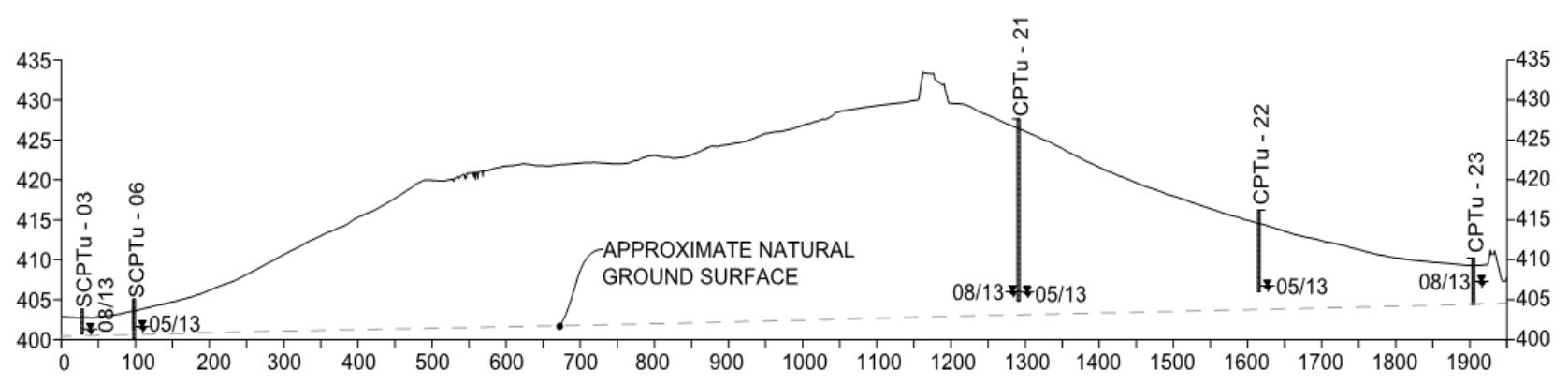

Figure 6 Location of phreatic surface in deposit

\subsection{Effective strength}

The triaxial strength tests returned peak effective strength values of $c^{\prime}=0$, and $\phi^{\prime}=28^{\circ}-29^{\circ}$.

Friction angles as low as $28^{\circ}$ are considered to be an under-estimate, possibly due to sampling disturbance, or disturbance associated with sample extrusion, set-up and saturation in the triaxial test. ATCW have numerous test results on reconstituted, normally consolidated tailings from similar 'hard rock' sources, for which friction angles in the range $35-38^{\circ}$ are typical. It should be noted that these results were obtained for the purpose of calculating the stability of access ramps to be placed over the tailings. These results were not a direct input into the liquefaction analysis of the whole beach.

\subsection{Consolidation/permeability}

Permeability values were calculated from CPTu dissipation tests (Robertson 2010) and were found to be relatively consistent, in the range $1 \times 10^{-7}$ to $1 \times 10^{-8} \mathrm{~m} / \mathrm{s}$. These are considered to be typical results for well graded, consolidated tailings from primary ore.

\section{$7 \quad$ CPTu results}

\subsection{General distribution}

A selection of CPT results (cone resistance $q_{c} v$ depth) at different distances from the discharge point (and hence different elevations on the stack) is presented in Figure 7. These are the 'highlighted' probes identified on Figure 1. The peaks on these plots are probably caused by buried salt crusts. The 'base' parts of the curves represent the tailings characteristics in un-crusted sections of the profile.

It is worth recalling here that these results have been derived from probes spread across a beach having dimensions of close to $2 \times 2 \mathrm{~km}$.

\subsection{Shear strength evaluation}

The results from Figure 7 are shown again in Figure 8, overlain on a single plot.

An inspection of these plots indicates two notable results:

1. All of the plots indicate a degree of over-consolidation / elevated strength at shallow depths in the probes (typically the top 5-10 m).

2. The remarkable uniformity of the results, with only the two probes from close to the bottom of the slope (CPTu 5 and CPTu 9 showing any reduction in shear strength near surface).

A full appreciation of these points requires some familiarity with the investigation methodology, but they should be readily apparent to anyone familiar with typical CPT results in conventional tailings deposits.

Interpretation of these results to obtain shear strength and liquefaction resistance is not necessarily as straightforward as in a normal case, because of the potential influence of partial saturation. 
Nevertheless, it can be argued that the suction resulting from partial saturation does represent the normal ('real') conditions in the tailings beach, and that correction of these values back to reflect a fully saturated case represents an unjustified degree of conservatism.

Consequently, this section, and the following Section 7.3, is based on the observed CPTu results. Considerations of the corrected results for a saturated profile are addressed in the following Section 8.

For dry or saturated fine grained soils, CPT results can be analysed to obtain undrained shear strength using the common equation:

$$
S_{u}=\left(q_{c}-\sigma_{v o}\right) / K
$$

Where:

$$
\begin{aligned}
& \mathrm{S}_{\mathrm{u}}=\text { undrained shear strength }(\mathrm{kPa}) . \\
& \mathrm{q}_{\mathrm{c}}=\text { cone resistance }(\mathrm{kPa}) . \\
& \sigma_{\mathrm{vo}}=\text { (total) vertical stress }(\mathrm{kPa}) . \\
& \mathrm{K} \quad=\text { cone factor (typically }=14) .
\end{aligned}
$$

Applying this equation to the near surface CPTu results indicates that the tailings have an absolute minimum apparent undrained strength of not less than $15 \mathrm{kPa}$, and a more typical lower bound apparent strength of $30 \mathrm{kPa}$ (Figure 8).

These results may be compared to limited previous vane shear results for the Sunrise beach (Williams et al. 2003) which showed a minimum strength of $6 \mathrm{kPa}$ and a mean between 12 and $16 \mathrm{kPa}$ over the top $2 \mathrm{~m}$ of the beach. The increase in strength since those results can be attributed to the reduction in rise rate as a result of beach development and increased surface area. Williams et al. (2003) also reported similar mean strength values (12-14 $\mathrm{kPa}$ ) for the CTD beach at Union Reefs.

A field-based confirmation of these values is provided by the trafficability of the surface and the stability of the excavated tailings face in the borrow area. A stable cut height of $5 \mathrm{~m}$ requires an undrained strength of the order of $20 \mathrm{kPa}$, which correlates well with the CPTu results.

Also shown in Figure 8 are lines for the undrained strength ratios $\left(\mathrm{S}_{\mathrm{u}} / \sigma_{\mathrm{vo}}\right)$ ) of the underlying normally consolidated zone. Lines for ratios of 0.25 and 0.35 are shown. The value 0.35 might be considered a typical lower bound to all the data, whereas the lower values could be taken as conservative numbers for the purpose of calculation of resistance to liquefaction.

These results suggest that the top 3-5 m of the stack is over-consolidated due to the desiccation effect.

\subsection{Liquefaction evaluation}

The liquefaction evaluation was carried out for both the operating basis earthquake (OBE) and maximum design earthquake (MDE) as defined in Australian National Committee on Large Dams (1998). Sunrise Dam is not in a highly active seismic area, and the values of peak ground acceleration (pga) used in the liquefaction assessment were $0.0275 \mathrm{~g}$ for the OBE and $0.07 \mathrm{~g}$ for the MDE case.

An initial assessment of liquefaction potential was undertaken based on the criteria of Seed et al. (2003). This provides a classification considering plasticity (Atterberg Limits) and particle size of the tailings, based on the observation that fine grained materials with a degree of plasticity are not susceptible to liquefaction. 


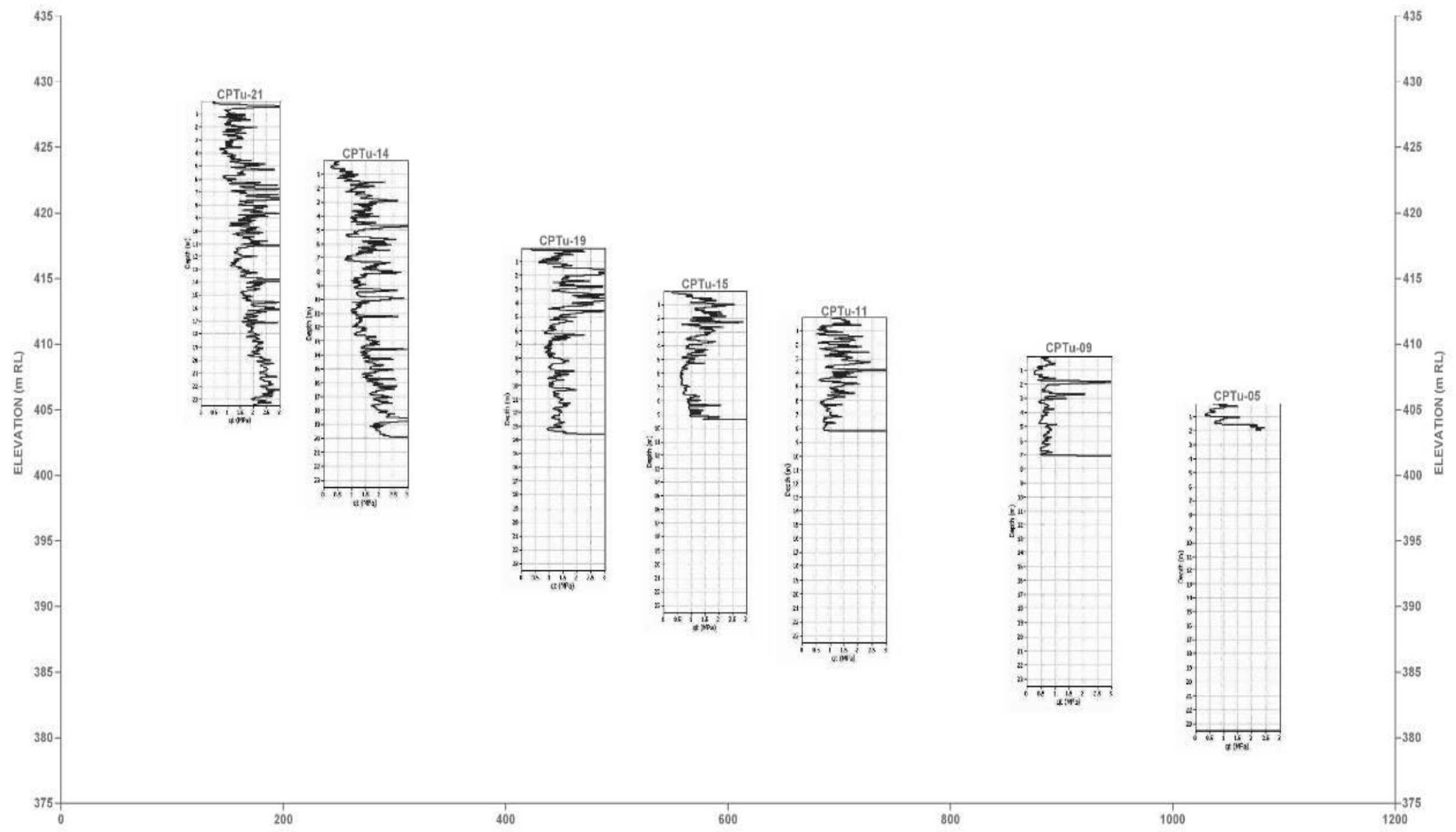

Figure 7 Selected CPT results 


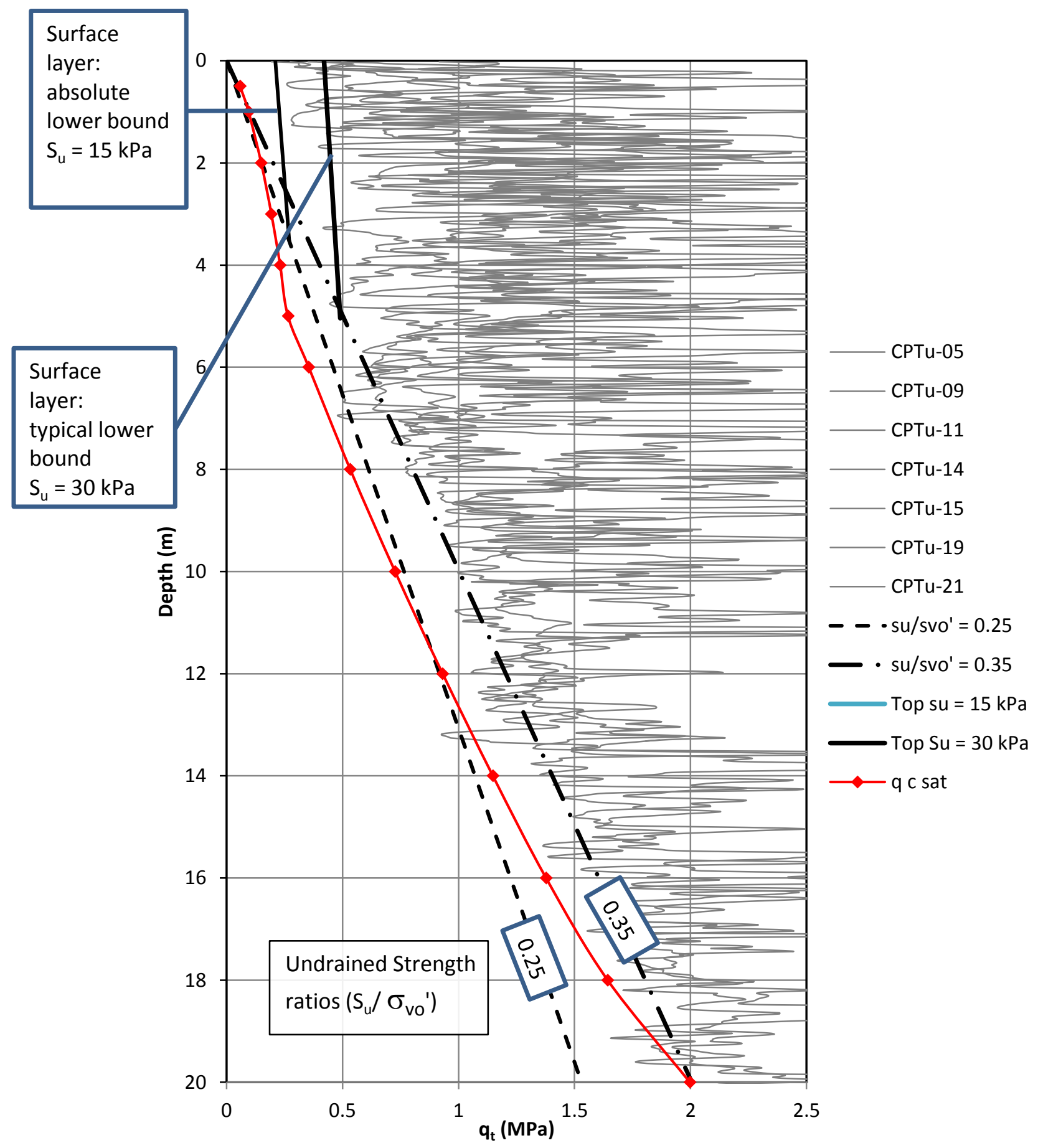

Figure 8 Selected CPT results

However, as noted above, the Sunrise Dam tailings classify as 'silty sand, ML', and it was no surprise that they did not fit the exclusion criteria, and further evaluation was required.

The CPT results were then used for a liquefaction evaluation using the Robertson and Wride method (Youd et al. 2001), without any correction for the degree of saturation. The results indicated that liquefaction would not be expected to occur at any location within the tailings profile under both OBE and MDE conditions.

A final check was undertaken using the shear wave velocity range of $160-180 \mathrm{~m} / \mathrm{s}$ obtained from the geotechnical investigation, using the method proposed by Youd et al. (2001). Again, this method indicated that liquefaction would not occur under either OBE or MDE conditions. 


\section{Effects of partial saturation}

\subsection{General}

One aspect still subject to some uncertainty is the degree to which the observed surface strengths are attributable to over-consolidation (and hence are 'permanent') or whether the effect is due only to suction (and hence is 'temporary' and can be destroyed by saturation). The authors have found that when tested for shrinkage limit density, typical tailings compress (shrink) under applied suctions but remain close to fully saturated until close to the shrinkage limit. Only then does the material begin to desaturate (Seddon \& Dillon 2009). A full soil moisture characteristic curve would provide valuable additional information on this aspect, but unfortunately the testing did not extend to this. Given that the investigation was carried out on a live beach, it could be argued that the 'absolute' lower bound envelope shown on Figure 8 relates to saturated tailings, whereas the 'typical' lower bound (and values higher than the lower bound) may include the effects of partial saturation.

\subsection{Correction of CPT results}

Russell et al. (2010) have proposed a method of correcting CPT penetration resistance values results from tests in partially saturated soils ( $q_{c}$ unsat) back to the equivalent value in saturated soils ( $q_{c}$ sat). They propose:

$$
\begin{gathered}
\mathrm{q}_{\mathrm{c} \mathrm{sat}}=\mathrm{CF} \times \mathrm{q}_{\mathrm{c} \text { unsat }} \\
\mathrm{CF}=1 /\left[\left(p_{\mathrm{o}}+\chi \mathrm{s}\right) / \mathrm{p}_{\mathrm{o}}^{\prime}\right] 0.7
\end{gathered}
$$

Where:

$$
\begin{aligned}
& \mathrm{CF} \quad=\text { correction factor. } \\
& \mathrm{p}_{\mathrm{o}} \quad=\text { vertical total stress }(\mathrm{kPa}) . \\
& \mathrm{p}_{\mathrm{o}}^{\prime} \quad=\text { vertical effective stress, for the saturated case }(\mathrm{kPa}) . \\
& \mathrm{s} \quad=\text { soil suction }(\mathrm{kPa}) . \\
& \chi \quad=\text { unsaturated effective stress correction factor. } \\
& \chi \mathrm{s} \quad=\text { apparent value of suction }(\mathrm{kPa}) .
\end{aligned}
$$

Furthermore, the unsaturated effective stress correction factor $\chi$ is calculated using:

$$
\chi=\left(\mathrm{s} / \mathrm{s}_{\mathrm{e}}\right)^{-0.55}
$$

Where:

$$
\text { Se } \quad=\text { suction value at which desaturation commences (sometimes called the air-entry value). }
$$

Russell et al. (2010) indicated that for fine grained materials this equation is valid for values of $\mathrm{s} / \mathrm{se}$ in the range 1-12.

In this instance we have adopted a value of $\mathrm{se}_{\mathrm{e}}=25 \mathrm{kPa}$ based on test results from similar tailings, and have calculated the actual suction $\mathrm{s}$ by reference to the elevation above the saturated zone that was encountered at the base of the tailings. For simplicity, we have assumed a uniform depth to the saturated zone of $20 \mathrm{~m}$, hence:

$$
\mathrm{s}=(20-\mathrm{z}) \times 9.8
$$

Where:

$\mathrm{z} \quad=$ depth below the tailings surface $(\mathrm{m})$. 
The calculation has been carried out using a cone resistance equal to the 'lower bound' lines shown on Figure 8. The results for the corrected cone penetration resistance, $\mathrm{q}_{\mathrm{c} \text { sat }}$ are also shown on Figure 8.

The calculated undrained strengths have been calculated in accordance with Equation 1 and are plotted on Figure 9. These results tend to indicate that the observed high cone resistance values and strengths are significantly influenced by suction, particularly near-surface, and that if saturated, the strength profile will revert to essentially a normally consolidated condition. This result is not in accordance with the observation that the tailings surface remained trafficable even in places where deposition had recently occurred, but it should be recognised that the presence of wet recently deposited tailings on the surface does not necessarily mean that the underlying tailings have to be saturated.

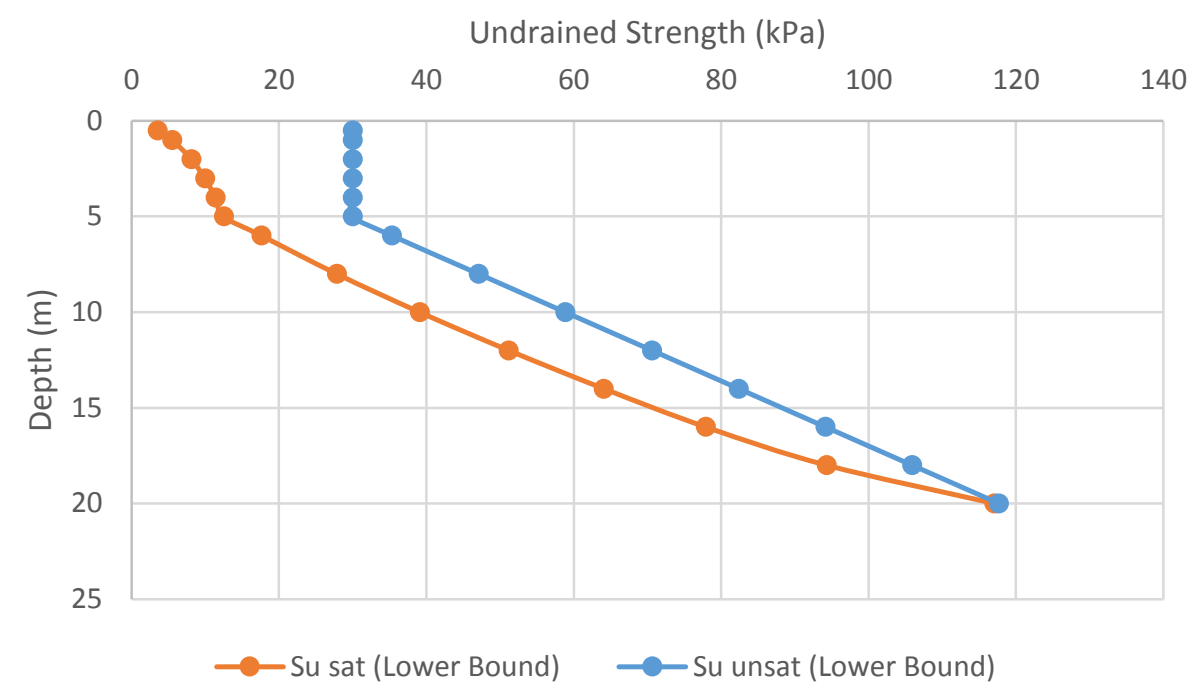

\section{Figure 9 Comparison of saturated and un-saturated (lower bound) strength}

More information could be obtained by installation of instrumentation to monitor in situ value of suction and moisture content (both with time and position), but this was beyond the scope of the subject investigation. Also, it is recommended that actual test values of the soil moisture characteristic curve should be obtained in any future evaluation, to provide better estimates of the air-entry value, $\mathrm{s}_{\mathrm{e}}$.

\subsection{Post liquefaction stability}

Lastly, it is noted that a post-liquefaction stability analysis was carried out for the tailings beach. This analysis is based on tailings strength assuming that the tailings have liquefied (regardless of the results quoted above that indicate that this will not occur at less than the MDE). The method of Olsen and Stark (2002) was used to evaluate liquefied strength values, based on the absolute lower bound CPTu results (Figure 8), but not the corrected qc sat values. A value of $q_{c}=0.25 \mathrm{MPa}$ was used for the upper $4 \mathrm{~m}$, giving an undrained strength ratio $\mathrm{Su} / \sigma_{\mathrm{vo}}{ }^{\prime}=0.035$. The resulting factor of safety against liquefaction flow failure was calculated using the equations for an 'infinite slope' condition (Seddon 2007). The results showed that all the slopes would be stable, and liquefaction flow sliding will not occur.

\section{$9 \quad$ Conclusions}

The results confirm that the Sunrise dam CTD beach is behaving in almost complete accordance with the overall expectations regarding the conditions on thickened tailings beaches.

Good beach slope development has been attained, and the flexibility of the method has enabled the original design capacity to be significantly expanded to cater for increased input rates, and an extended life of mine.

The results confirm that the tailings are non-segregating. 
A high storage density has been achieved, limited only by the effects of salinity. Almost all of the tailings in the deposit are unsaturated. A phreatic surface was only encountered very close to the natural soil base, in a limited number of boreholes.

The test results confirm relatively high in situ undrained shear strengths, particularly compared to the very soft materials typically encountered in 'slimes' ponds associated with segregating discharge schemes.

Analysis has indicated that the tailings are not liquefiable, and in any event would be stable against flow liquefaction.

Preliminary calculations suggest that some of the observed strength would be lost if the tailings were to become fully saturated, but more work is required to fully quantify this.

\section{Acknowledgement}

The authors would like to thank the management and staff at SDGM for their input and assistance.

\section{References}

Australian National Committee on Large Dams 1998, Guidelines on Design of Dams for Earthquake, ANCOLD, Hobart.

Brouwer, JMJ 2007, In-situ soil testing, Lankelma Ltd, East Sussex, viewed 25 January 2015, http://www.conepenetration.com /online-book/

Jewell, RJ \& Fourie, AB 2006, Paste and thickened tailings - a guide, 2nd edn, Australian Centre for Geomechanics, Perth.

Olson, SM \& Stark, TD 2002, 'Liquefied strength ratio from liquefaction flow failure case histories', Canadian Geotechnical Journal, vol. 39, no. 3, pp. 629-647.

Robertson, PK 2010, 'Estimating in-situ soil permeability from CPT \& CPTu', Proceedings of the 2nd International Symposium on Cone Penetration Testing, V2/51.

Robinsky, El 2000, 'Sustainable development in disposal of tailings', Proceedings of Tailings and Mine Waste '00, A.A. Balkema, Rotterdam.

Russell, AR, Pournaghiazar, M \& Khalili, N 2010, 'Interpreting CPT results in unsaturated sands', Proceedings of the 2nd International Symposium on Cone Penetration Testing.

Seed, RB, Cetin, KO, Moss, RE, Kammerer, AM, Wu, J, Pestana, JM \& Faris, A 2003, 'Recent advances in soil liquefaction engineering: a unified and consistent framework', Proceedings of the 26th Annual ASCE Los Angeles Geotechnical Spring Seminar.

Seddon, KD 2007, 'Post liquefaction stability of thickened tailings beaches', in AB Fourie \& RJ Jewell (eds), Proceedings of the Tenth International Seminar on Paste and Thickened Tailings, Australian Centre for Geomechanics, Perth, pp. 395-406.

Seddon, KD \& Dillon, MJ 2009, 'The effect of evaporation on strength and the stability of thickened tailings beach slopes', in RJ Jewell, AB Fourie, S Barrera \& J Wiertz (eds), Proceedings of the Twelfth International Seminar on Paste and Thickened Tailings, Australian Centre for Geomechanics, Perth, pp. 261-270.

Seddon, KD \& Williams, MPA 2010, 'The development and design of thickened tailings discharge methods - a review', in AB Fourie \& RJ Jewell (eds), Proceedings of the 1st International Seminar on the Reduction of Risk in the Management of Tailings and Mine Waste, Australian Centre for Geomechanics, Perth, pp. 487-498.

Seddon, KD \& Fitton, TG 2011, 'Realistic beach slope prediction and design', in R Jewell \& A Fourie (eds), Proceedings of the 14th International seminar on paste and thickened tailings, Australian Centre for Geomechanics, Perth, pp. 281-294.

Williams, MPA 2000, 'Evolution of thickened tailings disposal in Australia', in Paste Technology 2000, Australian Centre for Geomechanics, Perth, Section 15

Williams, MPA, Seddon, KD \& Murphy, S 2003, 'Paste and thickened tailings disposal: delivering the benefits', Proceedings of the 7th International Seminar on Paste and Thickened Tailings, Australian Centre for Geomechanics, Perth, Section 25.

Williams, MPA \& Seddon, KD 2004, 'Delivering the benefits (2): case history of Century Zinc and Sunrise Dam Gold Mine', Proceedings of the International Seminar on Paste and Thickened Tailings, Australian Centre for Geomechanics, Perth, paper 13.

Williams, MPA, Seddon, KD \& Fitton, TG 2008, 'Surface disposal of paste and thickened tailings - a brief history and current confronting issues', in AB Fourie, RJ Jewell, PT Slatter and A Paterson (eds), Proceedings of the 11th International Seminar on Paste and Thickened Tailings, Australian Centre for Geomechanics, Perth, pp. 143-164.

Youd, TL, Idriss, IM, Andrus, RD, Arango, I, Castro, G, Christian, JT \& Stokoe, KH 2001, 'Liquefaction resistance of soils: summary report from the 1996 NCEER and 1998 NCEER/NSF workshops on evaluation of liquefaction resistance of soils', Journal of Geotechnical and Geoenvironmental Engineering, vol. 127, no. 10, pp. 817-833. 